\title{
Effects of Plyometric Training on Rock'n'Roll Performance
}

\author{
Nico Nitzsche (Corresponding author) \\ Chemnitz University of Technology, Department of Human Movement Science and Health \\ Thüringer Weg 11, 09130 Chemnitz, Germany \\ E-mail: nico.nitzsche@s2007.tu-chemnitz.de \\ Norman Stutzig (Corresponding author) \\ University of Stuttgart, Department of Sport and Motion Science \\ Allmandring 28, 70569 Stuttgart, Germany \\ Achim Walther \\ University Hospital Carl Gustav Carus Dresden, Department of Sports medicine \\ Fetcherstraße 74, 01307 Dresden, Germany \\ Tobias Siebert \\ University of Stuttgart, Department of Sport and Motion Science \\ Allmandring 28, 70569 Stuttgart, Germany
}

Received: 09-09- 2015

Accepted: 28-09- 2015

Published: 31-10- 2015

doi:10.7575/aiac.ijkss.v.3n.4p.8

URL: http://dx.doi.org/10.7575/aiac.ijkss.v.3n.4p.8

\begin{abstract}
Objectives: The aim of the study was to analyse if plyometric training increases the sport specific performance in rock'n'roll dancers. Design: Fifteen semi-professional rock'n'roll dancers participated in a plyometric training study. Pre- and posttests were conducted to document alterations of sport specific performance, reactive strength as well as maximal isokinetic torque. Method: The participants $(n=15)$ accomplished two training sessions weekly for a training period of 6 weeks. The training program consisted of different of jumps. Pre- and posttests included a rock'n'roll specific performance test examining the maximal number of kicks within $30 \mathrm{~s}$. Moreover, jumping height and ground contact time (GCT) during drop jump were determined to calculate reactive strength (RSI). Maximal dynamic torque and work were determined during maximal isokinetic contractions of the plantar flexors. Results: The number of kicks increased from $46.5 \pm 2.6$ to $49.4 \pm 2.7\left(\mathrm{p}=0.00, \mathrm{~d}_{\mathrm{Z}}=1.83\right)$. The RSI increased significantly from $2.57 \pm 0.29$ to $2.72 \pm$ $0.44\left(\mathrm{p}=0.05, \mathrm{~d}_{\mathrm{Z}}=0.55\right)$. The gains of RSI are based on increases in jumping height (pretest: $24.6 \pm 4.0 \mathrm{~cm}$, posttest 26.5 $\left.\pm 4.7 \mathrm{~cm}, \mathrm{p}=0.01, \mathrm{~d}_{\mathrm{z}}=0.71\right)$, whereas the GCT remained unaltered $(\mathrm{p}=0.53)$. The work during maximal isokinetic plantar flexions increased significantly in both legs (jumping leg: $\mathrm{p}=0.04, \mathrm{~d}_{\mathrm{Z}}=0.58$; kicking leg: $\mathrm{p}=0.05, \mathrm{~d}_{\mathrm{Z}}=0.55$ ). Conclusions: Plyometric training increases the kicking frequency during rock'n'roll dance. This might be attributed to the observed increase in reactive strength. Training induced changes in muscle activity or structure were discussed. It is suggested to implement plyometric training into the training program of rock'n'roll dancers.
\end{abstract}

Keywords: Rock'n'roll, plyometric training, reactive strength, plantar flexors

\section{Introduction}

Physical abilities as strength and power contribute to the complex performance in many sports (Baechle \& Earle, 2008). The significance of their contribution depends on the performance system of the competition (Matveev, 1981). The strength efforts in high performance rock'n'roll dancing are mainly short ground contacts during hopping and jumps. A main performance criterion is the dancing velocity regarding to the number of kicks per minute. High performance athletes have to perform kicking frequencies of more than 100 kicks per minute (Kirch, 1995; WRRC, 2012). As the frequency of kicks is equal to the frequency of hops, rock'n'roll dancers perform hops at a frequency of more than 100 per minute. The frequency of kicks or rather hops per minute depends on the reactive strength of the athletes. Reactive strength is the ability to reverse eccentric into concentric muscle actions (Gamble, 2010; Young \& Farrow, 2006). Zemkova et al. (2001; 2005) showed that reactive strength and explosive power is higher in rock'n'roll dancers compared to other populations.

The aim of plyometric training is to maximize the reactive strength and power. Reactive strength can be measured using the reactive strength index (RSI). The RSI is the ratio between jumping height and time of touch down (GCT) within a stretch-shortening-cycle (for example during a drop jump). The index can be maximized by increasing jumping height while the GCT remained unaltered or by reducing the GCT while the jumping height is constant. In both cases the force during the ground contact needs to be increased. In literature it is reported that plyometric exercises are effective to 
develop reactive strength (Lloyd, Oliver, Hughes, \& Williams, 2012) and power (Bobbert, 1990; Bobbert, Huijing, \& van Ingen Schenau, 1987a, 1987b; Malisoux, Francaux, Nielens, \& Theisen, 2006). Plyometric exercise is defined as a quick powerful movement that involves the stretch-shortening cycle (Baechle \& Earle, 2008; Komi, 1984, 2003). It was shown that plyometric training increases the jump performance (Markovic, 2007; Matavulj, Kukolj, Ugarkovic, Tihanyi, \& Jaric, 2001), RSI as well as sprint abilities (Ronnestad, Kvamme, Sunde, \& Raastad, 2008). Increasing the RSI may increase the number of hops in a given time and may lead to increase the number of kicks in rock'n'roll. So far, it is unknown if plyometric training has a benefit effect on number of kicks in rock'n'roll. The aim of the study is to increase the number of kicks in young athletes by a sport specific plyometric training in rock'n'roll. It is hypothesised that plyometric training increases the RSI and the number of kicks in rock'n'roll.

\section{Methods}

Fifteen semi-professional rock'n'roll dancers (sex: 3 male, 12 female, age: $17.1 \pm 3.0$ year, weight: $58.8 \pm 7.4 \mathrm{~kg}$, height: $167 \pm 5 \mathrm{~cm}$, BMI: $17.8 \pm 1.9 \mathrm{~kg} / \mathrm{m}^{2}$ ) participated in the study. All athletes trained at least three times per week. All participants that suffered on a leg injury in the past six months before the study started were excluded from the study. The participants were informed about the aims and risks of the study and gave their written consent before the study started. The study was approved by the local ethical committee of the university hospital of Dresden and conducted in accordance with the latest declaration of Helsinki.

Participants were examined before and after the plyometric training intervention regarding to reactive strength, maximum strength and a sport specific performance test. The training was conducted two times per week with at least one day rest between the training sessions. The training intervention lasted for 6 weeks and was integrated into regular dance training (Brown, Wells, Schade, Smith, \& P.C., 2007). All participants completed the training phase.

Each training session started with a general warm-up containing running with moderate intensity followed by dynamic stretching of the leg muscles. Subsequently simple jumping exercises with moderate intensities were performed.

The training program started with 6 repetitions of jumping exercises. Three sets were performed. There was a 3 min rest between the sets. The participants were motivated to perform the jumping exercises with maximal power. According to the recommendations of the American College of Sports Medicine the volume was increased progressively from 42 jumps in the first week to 81 jumps in the last week (Ratamess et al., 2009). Moreover, different jumping exercises as squat jumps, tuck jumps, hurdle jumps and lateral jumps were chosen (Bosco, 1999). Hence, the kind of jumping exercise was also increased progressively in order to the intensity. Therefore, participants started with squat jumps at the beginning and performed multiple hurdle jumps with maximal explosive power in the last week. The overall design of the training program is shown in table 1.

Table 1. Training program performed by rock'n'roll dancers

\begin{tabular}{|c|c|c|c|c|}
\hline Week & Repetition & Sets & & Jumps total \\
\hline \multirow{2}{*}{1} & 6 & 3 & Squat Jumps & \multirow{2}{*}{42} \\
\hline & 8 & 3 & Lateral Jumps & \\
\hline \multirow{2}{*}{2} & 8 & 3 & Squat Jumps & \multirow{2}{*}{54} \\
\hline & 10 & 3 & Lateral Jumps & \\
\hline \multirow{2}{*}{3} & 10 & 3 & Squat Jumps & \multirow{2}{*}{66} \\
\hline & 12 & 3 & Lateral Jumps & \\
\hline \multirow{2}{*}{4} & 8 & 3 & Tuck Jumps & \multirow{2}{*}{51} \\
\hline & $3 \times 3$ & 3 & Hurdle Jumps & \\
\hline \multirow{2}{*}{5} & 10 & 3 & Tuck Jumps & \multirow{2}{*}{66} \\
\hline & $4 \times 3$ & 3 & Hurdle Jumps & \\
\hline \multirow{2}{*}{6} & 12 & 3 & Tuck Jumps & \multirow{2}{*}{81} \\
\hline & $5 \times 3$ & 3 & Hurdle Jumps & \\
\hline
\end{tabular}

\subsection{Pretest / Posttest}

All participants were tested before and after the end of the training intervention. After a standardized warm-up different functional tests were performed.

To assess the effect of training on dancing performance a rock'n'roll specific performance test was conducted. This sport specific motor test is a main criterion for rock'n'roll dancers and closely related to the dance performance (Kirch, 
1995). The aim of the test was to complete as many as possible rock'n'roll kicks within 30 seconds. Participants executed the test two times with 5 min rest between the trials. The mean number of kicks of the two trials was used for further analyses.

Maximal dynamic torque (MVDC) during plantar flexion was determined using an isokinetic diagnostic system (ISOMED2000, D\&R Ferstl GmbH, Hemau, Germany) (Stutzig \& Siebert, 2015). Participants lie supine in the ISOMED2000 with one foot attached to a pedal. The hip and knee angle were completely straight and fixed with straps. The range of motion of the ankle amounted $55^{\circ}$. The dynamic plantar flexion was carried out at an angular velocity of $240 \%$. One set consisting of seven repetitions was conducted. The maximum torque and work were calculated for each repetition. For further analyses the data of the third until the seventh repetition were averaged.

The reactive strength (Young \& Farrow, 2006) within a stretch-shortening cycle (Komi, 2000) was assessed using drop jump exercises (Fleck \& Kraemer, 2004). Participants stood on a box (height: $30 \mathrm{~cm}$ ) until jump off (Flanagan, Ebben, \& Jensen, 2008). They were asked to touch down and jump off as fast as possible and hence, to jump as high as possible (Taube, Leukel, Lauber, \& Gollhofer, 2011). The GCT and the flight time $\left(\mathrm{t}_{\text {flight }}\right)$ were assessed using a force plate (Kistler@ Typ 9281EA). The data were recorded by a sample rate of $1000 \mathrm{~Hz}$ and stored on a computer. The jumping height $(\mathrm{H})$ was calculated based on the flight time:

$H=\frac{1}{8} * g * t_{\text {flight }}^{2}$

where $\mathrm{g}$ is the gravitational acceleration and $\mathrm{t}_{\text {flight }}$ is the flight time. Furthermore, a reactive strength index (RSI) was calculated as follows (Abramov, Kuporosov, \& Matwejew, 1980; Bruhn, Kullmann, \& Gollhofer, 2004; Flanagan et al., 2008):

$R S I=\frac{H}{t_{g e}}$

where $t_{\mathrm{gc}}$ is the ground contact time. Five single drop jumps were conducted with $30 \mathrm{~s}$ rest between the trials. The data of the jump with the best RSI was used for further analyses.

\subsection{Statistics}

The data are presented as mean and standard deviation. Moreover, data were proved for normal distribution using the Shapiro-Wilk test. A student t-test was used to detect differences between pre and posttests. The effect size $\left(\mathrm{d}_{\mathrm{z}}\right)$ was calculated as mean of the differences divided by the standard deviation of the differences (Cohen, 1988). The significant level was set at $\mathrm{p}=0.05$.

\section{Results}

The number of kicks increased significantly from $46.5 \pm 2.6$ kicks to $49.4 \pm 2.7\left(\mathrm{p}=0.00, \mathrm{~d}_{\mathrm{Z}}=1.83\right)$ kicks due to the specific power training (fig. 1).

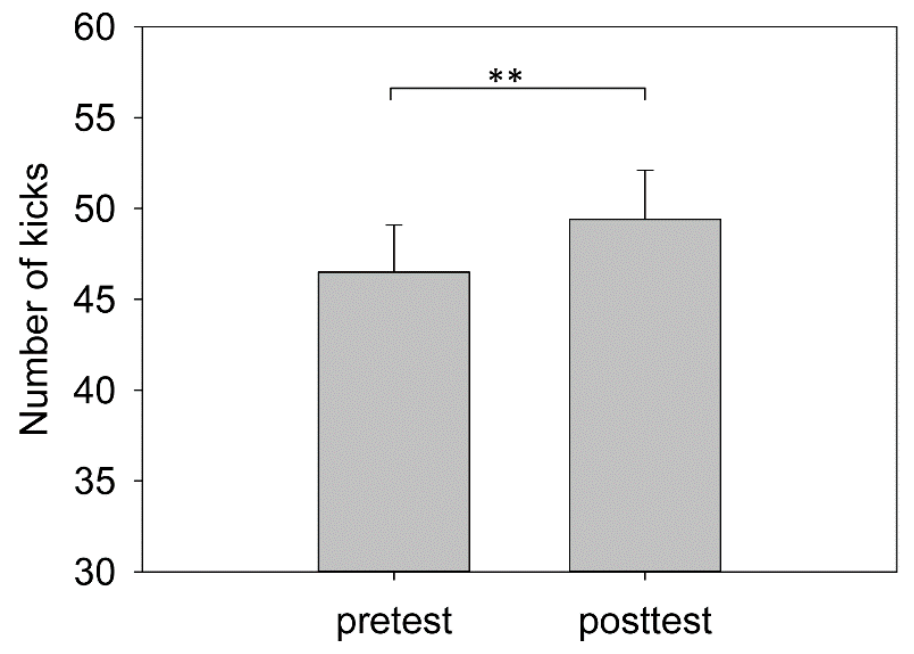

Figure 1. Mean and standard deviation of the number of kicks during the rock'n'roll specific performance test. The left bar shows the results of the test before the training intervention (pretest) and the right bar after the training intervention (posttest). ** Significant between pretest and posttest at $\mathrm{p}<0.01$. 
The peak torque during MVDC of the jumping leg increased significantly $\left(\mathrm{p}=0.02, \mathrm{~d}_{\mathrm{Z}}=0.65\right)$ from $41.3 \pm 10.9 \mathrm{Nm}$ to $49.9 \pm 8.1 \mathrm{Nm}$. However, the peak torque of the kicking leg did not increase significantly $(\mathrm{p}=0.10)$ (fig.2).

The work during the MVDC increased in both jumping leg $\left(\mathrm{p}=0.04, \mathrm{~d}_{\mathrm{z}}=0.58\right.$, pre: $27.1 \pm 7.4$, post: $\left.31.2 \pm 5.1\right)$ and kicking leg ( $p=0.05, d_{z}=0.55$ pre: $28.3 \pm 8.7$, post: $\left.32.5 \pm 6.6\right)$ (fig. 3 ).

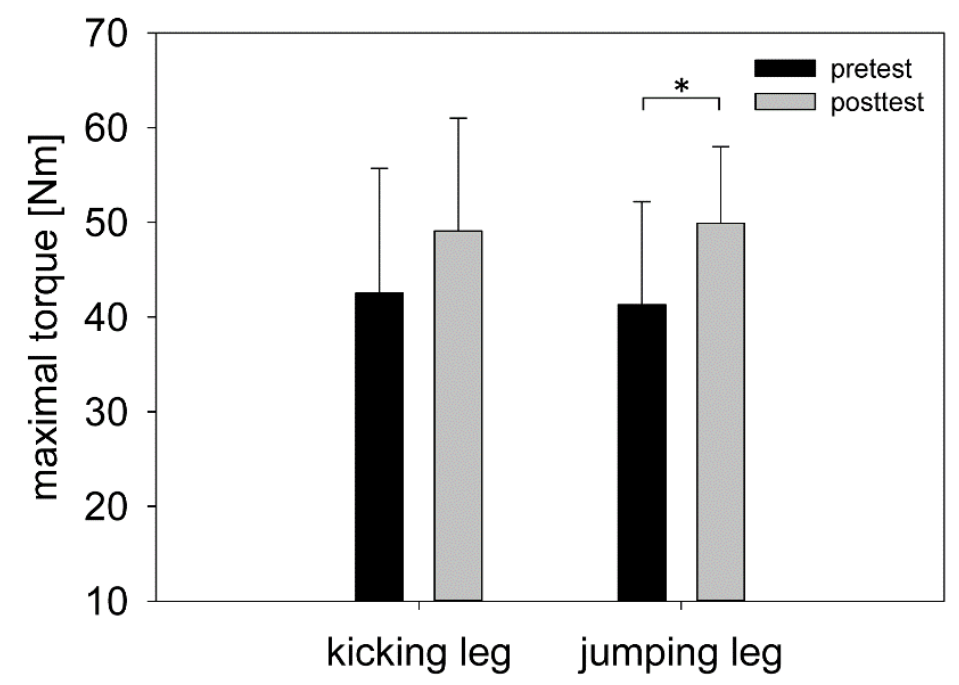

Figure 2. Mean and standard deviation of the maximal torque during the isokinetic plantar flexions of the kicking leg and jumping leg. The black and the grey bars show the results of the test before (pretest) and after (posttest) the training intervention, respectively. ${ }^{*}$ Significant between pretest and posttest at $\mathrm{p}<0.05$.

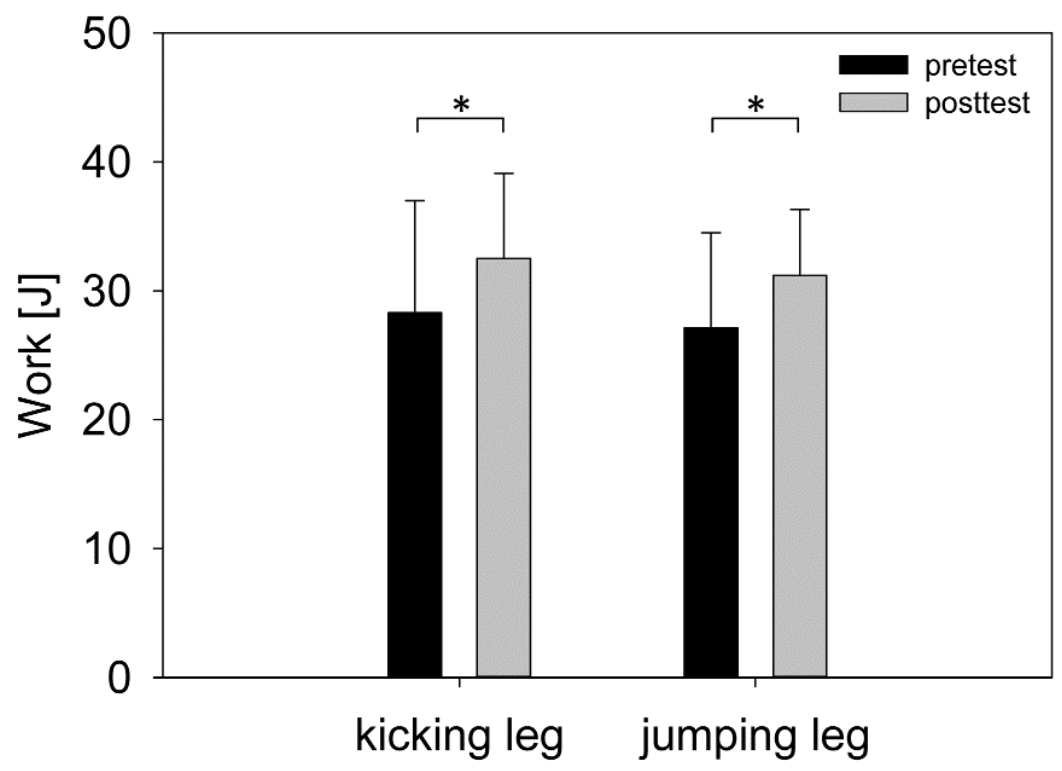

Figure 3. Mean and standard deviation of physical work during the isokinetic plantar flexions of the kicking leg and jumping leg. The black and the grey bars show the results of the test before (pretest) and after (posttest) the training intervention, respectively. ${ }^{*}$ Significant between pretest and posttest at $\mathrm{p}<0.05$.

The GCT during drop jump remained unaltered $\left(\mathrm{p}=0.53, \mathrm{~d}_{\mathrm{Z}}=0.17\right)$ throughout the training intervention. The jumping height increased significantly $\left(\mathrm{p}=0.01, \mathrm{~d}_{\mathrm{z}}=0.71\right.$ ) from $24.6 \pm 4.0 \mathrm{~cm}$ to $26.5 \pm 4.7 \mathrm{~cm}$. Moreover, the RSI increased significantly ( $\mathrm{p}=0.05, \mathrm{~d}_{\mathrm{Z}}=0.55$ ) from $2.57 \pm 0.29$ to $2.72 \pm 0.44$, too (tab.2).

Table 2. Mean, standard deviation (SD) and level of significance (p) of the Drop Jump during pretest and posttest

\begin{tabular}{ccccc}
\hline Test & Parameter & Pretest & Posttest & $\mathrm{p}$ \\
\hline & Ground contact time [s] & $0.173 \pm 0.015$ & $0.170 \pm 0.018$ & 0.53 \\
Drop Jump & Jumping height [cm] & $24.6 \pm 4.0$ & $26.5 \pm 4.7$ & 0.01 \\
& Reactive strength index & $2.57 \pm 0.29$ & $2.72 \pm 0.44$ & 0.05 \\
\hline
\end{tabular}




\section{Discussion}

This study demonstrates, that a plyometric training improves the sport specific performance of rock'n'roll dancers, e.g. by increasing the number of kicks. The athletes increased their speed from 46.5 to 49.4 kick (in $30 \mathrm{sec}$ ). The number of kicks corresponds to an increase of kicking frequency from 93 to 98.8 kicks per minute. According to the international rules of rock'n'roll (WRRC, 2012) the speed of music amounts 50-52 bars per minute for international tournaments. One basic step contains three kicks and lasts 1.5 bars. At a music speed of 51 bars per minute 34 basic steps need to be performed. That means high performance athletes perform a kicking frequency of 102 kicks per minute.

One possible reason for the increased number of kicks may be the observed improvement in the reactive strength index (RSI). This was reported in other plyometric studies too (Lloyd et al., 2012; Markovic, Jukic, Milanovic, \& Metikos, 2007). RSI depends on GCT and jumping height (Abramov et al., 1980; Flanagan et al., 2008; Markovic, 2007). Markovic et al. (2007) conducted a plyometric training program 3 times weekly for 10 weeks. Before and after the training intervention the participants $(n=30)$ performed maximal drop jumps. In our study the RSI increased, too. However, in the study of Markovic et al. (2007) the GCT decreased while the jumping height remained unaltered. We observed gains in jumping height and unaltered GCT. The discrepancies might be explained by the different populations participating in the two studies. In our study semi- professional dancers which were experienced in jumping were examined while Markovic et al. (2007) analyzed physical educational students who had no specific jump experience. On the other hand Kyrolainen et al. (2005) accomplished a training program for 10 weeks with recreational man. According to our and other studies (Kubo et al., 2007) they observed gains in jumping height while the GCT remained unaltered. Further, another training study with intermediate or advanced ballet or modern dancers (Brown et al., 2007) found an increase in standing vertical jumping height of $8.3 \%$ after 6 weeks of plyometric training.

An increase in jumping height is based on an increase in force impact equaling the impulse (momentum). As the observed GCT of the drop jump is constant, the increase in the impulse is attributable to an increase in the mean force. This is in accordance with increased forces measured during maximal voluntary plantar flexions. In these measurements the increased work (Fig. 3) results from an increased force, too, as the angular velocity as well as the angular range of motion were given by the isokinetic diagnostic system during the plantar flexions. Furthermore, the peak torque was increased significantly for the jumping leg and tends to increase for the kicking leg (Fig. 2). An increase in maximum force (isometric and dynamic) after plyometric training was reported by a series of studies (Kubo et al., 2007; Wilkerson et al., 2004), too. The increases of maximal force can be induced either by an increase of neuromuscular activation or changes in the muscle properties (Duchateau \& Baudry, 2011).

It is documented that a time course exist between adaptations of neural and muscle factors (Sale, 1988). In early stages of strength training the neuromuscular performance increase followed by gains in the cross sectional area (Moritani \& deVries, 1979).

Increased muscle activity after plyometric training was found using surface electromyography (Gollhofer \& Kyrolainen, 1991; Toumi, Best, Martin, F'Guyer, \& Poumarat, 2004). Kyrolainen et al. (2005) conducted a plyometric training over 15 weeks with 2 training sessions weekly. They found increased muscle activity in the plantar flexors accompanied by increased MVC force after 10 weeks of training. The changes of muscle activity of the gastrocnemius muscle and MVC force correlated well ( $\mathrm{r}=0.77, \mathrm{p}<0.01)$. Unfortunately, with the used methods it is not possible to distinguish if the gain in muscle activity is based on increased motor unit recruitment or increased firing rate (Duchateau \& Baudry, 2011). The muscle activity can be modulated on supraspinal and spinal level. In this context increased spinal reflex activity was found after plyometric training (Voigt, Chelli, \& Frigo, 1998). It was assumed that the increased muscle activity during a stretch-shortening cycle (as in drop jump) after plyometric training is based on changes in the spinal reflex activity (Voigt et al., 1998). It is not reported in literature if supraspinal adaptations occur due to plyometric training.

Moreover, improved neuromuscular performance may also caused by enhanced muscle coordination. Kyrolainen et al. (1998) observed decreased antagonistic activity during plyometric training of the upper limb muscles in untrained women. In our study jumping experienced dancers were trained. So we do not believe that improved muscle coordination is the main source of the increased jumping height and force gains. However, Kubo et al. (2007) compared weight training and plyometric training with regard to muscle activation and jump performance during drop jump. They found increased muscle activation in both training groups but the jumping height increased in the plyometric group only. Kubo et al. (2007) concluded that the improvements in jumping height are attributed to changes in the mechanical properties of the muscle-tendon complex, rather than muscle activation strategies.

First muscle strength may increase due to hypertrophy, namely the increase in the cross sectional area of individual muscle fibers. This was reported by (Andersen \& Aagaard, 2000; Hortobagyi et al., 1996; LaStayo, Pierotti, Pifer, Hoppeler, \& Lindstedt, 2000; Malisoux et al., 2006). However, there are some studies concluding that plyometric training does not lead to higher isometric strength or muscle hypertrophy (Hakkinen et al., 1990; Prilutsky, 2005).

Changes in muscle fiber type ratio, which could further influence muscle force (Bottinelli, Schiaffino, \& Reggiani, 1991; Malisoux, Francaux, \& Theisen, 2007), may have little influence, as Kyrolainen et al. (2005) found no changes in the muscle fibertype distribution after a 15 week plyometric training intervention.

In general plyometric training results in an increase in muscle-tendon stiffness (Benn et al., 1998; Lindstedt, LaStayo, \& Reich, 2001; Lindstedt, Reich, Keim, \& LaStayo, 2002; Pousson, Van Hoecke, \& Goubel, 1990; Reich, Lindstedt, LaStayo, \& Pierotti, 2000). This may be attributed to an increase of tendon stiffness, muscle stiffness, or both. 
Results regarding tendon stiffness after eccentric or plyometric training are ambiguous. In humans, tendon stiffness was reported to increase after training, whether it was eccentric training (Buchanan , Almdale, Lewis, \& Rymer, 1986; Duclay, Robbe, Pousson, \& Martin, 2009), endurance training (Buchanan \& Marsh, 2001) or strength training (Kubo, Kanehisa, Kawakami, \& Fukunaga, 2001). This increase may enhance the performance during stretch-shortening cycles by favoring the release of potential energy (Bosco, Komi, \& Ito, 1981; Duchateau \& Baudry, 2011). However, Kubo et al. (2007) found no change in tendon stiffness but in joint stiffness after plyometric training. Thus, they suggested that greatest adaptations in muscle-tendon stiffness may be located in the muscle.

Performing an 8 week eccentric training program with rats it could be demonstrated, that the stiffness of the muscle increased by $40 \%$ significantly (Reich et al., 2000), whereas muscle mass and isometric muscle force remained unchanged. The authors concluded that the 8 week training period is sufficient to induce structural adaptations in the muscle. They suggest that the increase in active muscle stiffness may be attributed to changes in the molecular spring titin. Rode et al. (2009) suggested a physiologically motivated muscle model which explains enhanced muscle stiffness by activation dependent titin-actin interaction. The giant protein titin is a structural part of myosin with a free part acting as a molecular spring connecting myosin to the Z-disc near the actin filament. The structure of its free part is very complex (Linke, Ivemeyer, Mundel, Stockmeier, \& Kolmerer, 1998). Different muscles exhibit different titin isoforms with different elastic properties (Prado et al., 2005). It is very interesting, if these isoforms are exclusively determined by the genotype, or may adapt dependent on muscle function or specific training programs as suspected by (Lindstedt et al., 2002; McBride, Triplett-McBride, Davie, Abernethy, \& Newton, 2003). A differential expression of titin protein bands in competitive athletes with increased levels of strength and power in comparison to untrained non-athletic individuals was observed by McBride et al. (2003). However, Kyrolainen et al. (2005) found no changes in the titin isoforms isolated from muscle biopsies after 15 weeks plyometric training. So far, further studies are needed to analyse modifications in the fine structure of the contractile and elastic components to find true mechanistic explanations due to plyometric training.

A limitation of this exercise study is that no control group was available. It takes the next step, a homogeneous comparison group of rock and roll dancers to be consulted, which is difficult to implement due to the availability in the rule.

\section{Conclusion}

In conclusion plyometric training leads to an increased number of rock'n'roll kicks. This increase might be attributed to gains in reactive strength as we found in our study. Despite considerable improvements in jumping performance, in dynamic peak torque as well as work during maximal concentric contractions, the results from this investigation do not reveal any further information about possible adaptations in muscle structure or neural drive of the plantar flexors. However, we suggest the implementation of plyometric training to improve the sport specific performance in rock'n'roll dancing.

\section{References}

Abramov, E., Kuporosov, B., \& Matwejew, V. (1980). Trenirovka bystroty ottalkivanija. Legkaja atletika(1), 20.

Andersen, J. L., \& Aagaard, P. (2000). Myosin heavy chain IIX overshoot in human skeletal muscle. Muscle Nerve, 23(7), 1095-1104.

Baechle, T. R., \& Earle, R. W. (2008). Essentials of strength training and conditioning (3. ed.). Champaign, IL: Human Kinetics.

Benn, C., Forman, K., Mathewson, D., Tapply, M., Tiskus, S., Whang, K., \& Blanpied, P. (1998). The effects of serial stretch loading on stretch work and stretch-shorten cycle performance in the knee musculature. Journal of Orthopaedic \& Sports Physical Therapy, 27(6), 412-422.

Bobbert, M. F. (1990). Drop jumping as a training method for jumping ability. Sports Medicine, 9(1), 7-22.

Bobbert, M. F., Huijing, P. A., \& van Ingen Schenau, G. J. (1987a). Drop jumping. I. The influence of jumping technique on the biomechanics of jumping. Medicine \& Science in Sports \& Exercise, 19(4), 332-338.

Bobbert, M. F., Huijing, P. A., \& van Ingen Schenau, G. J. (1987b). Drop jumping. II. The influence of dropping height on the biomechanics of drop jumping. Medicine \& Science in Sports \& Exercise, 19(4), 339-346.

Bosco, C. (1999). Strength assessment with Bosco's Test. Rome: Italian Society of Sport Science.

Bosco, C., Komi, P. V., \& Ito, A. (1981). Prestretch potentiation of human skeletal muscle during ballistic movement. Acta physiologica Scandinavica, 111(2), 135-140.

Bottinelli, R., Schiaffino, S., \& Reggiani, C. (1991). Force-velocity relations and myosin heavy chain isoform compositions of skinned fibres from rat skeletal muscle. The Journal of Physiology, 437, 655-672.

Brown, A. C., Wells, T. J., Schade, M. L., Smith, D. L., \& P.C., F. (2007). Effects of Plyometric Training Versus Traditional Weight Training on Strength, Power, and Aesthetic Jumping Ability in Female Collegiate Dancers. Journal of Dance Medicine \& Science, 11(2), 38-44. 
Bruhn, S., Kullmann, N., \& Gollhofer, A. (2004). The effects of a sensorimotor training and a strength training on postural stabilisation, maximum isometric contraction and jump performance. International Journal of Sports Medicine, 25(1), 56-60.

Buchanan, C. I., \& Marsh, R. L. (2001). Effects of long-term exercise on the biomechanical properties of the Achilles tendon of guinea fowl. Journal of applied physiology, 90(1), 164-171.

Buchanan, T. S., Almdale, D. P., Lewis, J. L., \& Rymer, W. Z. (1986). Characteristics of synergistic relations during isometric contractions of human elbow muscles. Journal of Neurophysiology, 56(5), 1225-1241.

Cohen, J. (1988). Statistical power analysis for the behavioral sciences (2. ed.). Hillsdale, NJ u.a.: Lawrence Erlbaum Associates.

Duchateau, J., \& Baudry, S. (2011). Training adaptation of the neuromuscular system. In P. V. Komi (Ed.), Neuromuscular aspects of sport performance (Vol. 17, pp. 216-253). Oxford: Wiley-Blackwell.

Duclay, J., Robbe, A., Pousson, M., \& Martin, A. (2009). Effect of angular velocity on soleus and medial gastrocnemius H-reflex during maximal concentric and eccentric muscle contraction. Journal of Electromyography and Kinesiology, 19(5), 948-956.

Flanagan, E. P., Ebben, W. P., \& Jensen, R. L. (2008). Reliability of the reactive strength index and time to stabilization during depth jumps. Journal of Strength \& Conditioning Research, 22(5), 1677-1682.

Fleck, S. J., \& Kraemer, W. J. (2004). Designing resistance training programs (3rd ed.). Champaign, IL: Human Kinetics.

Gamble, P. (2010). Strength and conditioning for team sports : sport-specific physical preparation for high performance. London u.a.: Routledge.

Gollhofer, A., \& Kyrolainen, H. (1991). Neuromuscular control of the human leg extensor muscles in jump exercises under various stretch-load conditions. International Journal of Sports Medicine, 12(1), 34-40.

Hakkinen, K., Pakarinen, A., Kyrolainen, H., Cheng, S., Kim, D. H., \& Komi, P. V. (1990). Neuromuscular adaptations and serum hormones in females during prolonged power training. International Journal of Sports Medicine, 11(2), 9198.

Hortobagyi, T., Hill, J. P., Houmard, J. A., Fraser, D. D., Lambert, N. J., \& Israel, R. G. (1996). Adaptive responses to muscle lengthening and shortening in humans. Journal of Applied Physiology, 80(3), 765-772.

Kirch, S. (1995). Handbuch für Rock'n'Roll. Aachen: Meyer \& Meyer.

Komi, P. V. (1984). Physiological and biomechanical correlates of muscle function: effects of muscle structure and stretch-shortening cycle on force and speed. Exercise and Sport Sciences Reviews, 12, 81-121.

Komi, P. V. (2000). Stretch-shortening cycle: a powerful model to study normal and fatigued muscle. Journal of Biomechanics, 33(10), 1197-1206.

Komi, P. V. (2003). Stretch-Shortening Cycle. In P. V. Komi (Ed.), Strength and Power in Sport (Vol. 2nd ed, pp. 184202). Oxford: Blackwell Science.

Kubo, K., Kanehisa, H., Kawakami, Y., \& Fukunaga, T. (2001). Effects of repeated muscle contractions on the tendon structures in humans. European Journal of Applied Physiology, 84(1-2), 162-166.

Kubo, K., Morimoto, M., Komuro, T., Yata, H., Tsunoda, N., Kanehisa, H., \& Fukunaga, T. (2007). Effects of plyometric and weight training on muscle-tendon complex and jump performance. Medicine \& Science in Sports \& Exercise, 39(10), 1801-1810.

Kyrolainen, H., Avela, J., McBride, J. M., Koskinen, S., Andersen, J. L., Sipila, S., . . Komi, P. V. (2005). Effects of power training on muscle structure and neuromuscular performance. Scandinavian Journal of Medicine \& Science in Sports, 15(1), 58-64.

Kyrolainen, H., Komi, P. V., Hakkinen, K., \& D., H. K. (1998). Effects of Power Training With Stretch-Shortening Cycle (SSC) Exercises of Upper Limbs in Untrained Women. Journal of Strength \& Conditioning Research, 12(4), 248-252.

LaStayo, P. C., Pierotti, D. J., Pifer, J., Hoppeler, H., \& Lindstedt, S. L. (2000). Eccentric ergometry: increases in locomotor muscle size and strength at low training intensities. American Journal of Physiology - Regulatory, Integrative and Comparative Physiology, 278(5), R1282-1288.

Lindstedt, S. L., LaStayo, P. C., \& Reich, T. E. (2001). When active muscles lengthen: properties and consequences of eccentric contractions. Physiology, 16(6), 256-261.

Lindstedt, S. L., Reich, T. E., Keim, P., \& LaStayo, P. C. (2002). Do muscles function as adaptable locomotor springs? Journal of Experimental Biology, 205(Pt 15), 2211-2216.

Linke, W. A., Ivemeyer, M., Mundel, P., Stockmeier, M. R., \& Kolmerer, B. (1998). Nature of PEVK-titin elasticity in skeletal muscle. Proceedings of the National Academy of Sciences USA, 95(14), 8052-8057.

Lloyd, R. S., Oliver, J. L., Hughes, M. G., \& Williams, C. A. (2012). The effects of 4-weeks of plyometric training on reactive strength index and leg stiffness in male youths. Journal of Strength and Conditioning Research, 26(10), 28122819. 
Malisoux, L., Francaux, M., Nielens, H., \& Theisen, D. (2006). Stretch-shortening cycle exercises: an effective training paradigm to enhance power output of human single muscle fibers. Journal of Applied Physiology, 100(3), 771-779.

Malisoux, L., Francaux, M., \& Theisen, D. (2007). What do single-fiber studies tell us about exercise training? Medicine \& Science in Sports \& Exercise, 39(7), 1051-1060.

Markovic, G. (2007). Does plyometric training improve vertical jump height? A meta-analytical review. British Journal of Sports Medicine, 41(6), 349-355.

Markovic, G., Jukic, I., Milanovic, D., \& Metikos, D. (2007). Effects of sprint and plyometric training on muscle function and athletic performance. Journal of Strength and Conditioning Research, 21(2), 543-549.

Matavulj, D., Kukolj, M., Ugarkovic, D., Tihanyi, J., \& Jaric, S. (2001). Effects of plyometric training on jumping performance in junior basketball players. The Journal of Sports Medicine and Physical Fitness, 41(2), 159-164.

Matveev, L. P. (1981). Grundlagen des sportlichen Trainings (1. Aufl. ed.). Berlin: Sportverl.

McBride, J. M., Triplett-McBride, T., Davie, A. J., Abernethy, P. J., \& Newton, R. U. (2003). Characteristics of titin in strength and power athletes. European journal of applied physiology, 88(6), 553-557.

Moritani, T., \& deVries, H. A. (1979). Neural factors versus hypertrophy in the time course of muscle strength gain. American Journal of Physical Medicine \& Rehabilitation, 58(3), 115-130.

Pousson, M., Van Hoecke, J., \& Goubel, F. (1990). Changes in elastic characteristics of human muscle induced by eccentric exercise. Journal of Biomechanics, 23(4), 343-348.

Prado, L. G., Makarenko, I., Andresen, C., Kruger, M., Opitz, C. A., \& Linke, W. A. (2005). Isoform diversity of giant proteins in relation to passive and active contractile properties of rabbit skeletal muscles. The Journal of General Physiology, 126(5), 461-480.

Prilutsky, B. (2005). Eccentric muscle action in sport and exercise. Biomechanics in sport: performance enhancement and injury prevention, $56-86$.

Ratamess, N. A., Alvar, B. A., Housh, T. J., Kibler, W. B., Kraemer, W. J., \& Triplett, N. T. (2009). American College of Sports Medicine position stand. Progression models in resistance training for healthy adults. Medicine \& Science in Sports \& Exercise, 41(3), 687-708.

Reich, T., Lindstedt, S., LaStayo, P., \& Pierotti, D. (2000). Is the spring quality of muscle plastic? American Journal of Physiology-Regulatory, Integrative and Comparative Physiology, 278(6), R1661-R1666.

Rode, C., Siebert, T., \& Blickhan, R. (2009). Titin-induced force enhancement and force depression: a 'sticky-spring' mechanism in muscle contractions? Journal of Experimental Biology, 259(2), 350-360.

Ronnestad, B. R., Kvamme, N. H., Sunde, A., \& Raastad, T. (2008). Short-term effects of strength and plyometric training on sprint and jump performance in professional soccer players. Journal of Strength \& Conditioning Research, 22(3), 773-780.

Sale, D. G. (1988). Neural adaptation to resistance training. Medicine \& Science in Sports \& Exercise, $20(5$ Suppl), S135-145.

Stutzig, N., \& Siebert, T. (2015). Influence of joint position on synergistic muscle activity after fatigue of a single muscle head. Muscle \& Nerve, 51(2), 259-267. doi: 10.1002/mus.24305

Taube, W., Leukel, C., Lauber, B., \& Gollhofer, A. (2011). The drop height determines neuromuscular adaptations and changes in jump performance in stretch-shortening cycle training. Scandinavian Journal of Medicine \& Science in Sports.

Toumi, H., Best, T. M., Martin, A., F'Guyer, S., \& Poumarat, G. (2004). Effects of eccentric phase velocity of plyometric training on the vertical jump. International Journal of Sports Medicine, 25(5), 391-398.

Voigt, M., Chelli, F., \& Frigo, C. (1998). Changes in the excitability of soleus muscle short latency stretch reflexes during human hopping after 4 weeks of hopping training. European Journal of Applied Physiological and Occupational Physiology, 78(6), 522-532.

Wilkerson, G. B., Colston, M. A., Short, N. I., Neal, K. L., Hoewischer, P. E., \& Pixley, J. J. (2004). Neuromuscular Changes in Female Collegiate Athletes Resulting From a Plyometric Jump-Training Program. Journal of Athletic Training, 39(1), 17-23.

WRRC. (2012). Rock'n'roll rules RR/1/0112. Retrieved from http://www.wrrc.org/data/wrrc.org/doc/Rules_Competition_RnR/30_RR_RULES_0112.pdf (January, 2012)

Young, W. B., \& Farrow, D. (2006). A Review of Agility: Practical Applications for Strength and Conditioning. Strength and conditioning journal, 28(5), 38-39.

Zemková, E., Dzurenková, D., \& Pelikán, H. (2001). Assessment of jump abilities in rock'n'roll performers. Homeostasis, 41(6), 265-267.

Zemková, E., \& Hamar, D. (2005). Jump ergometer in sport performance testing. Acta Universitatis Palackianae Olomucensis, Gymnica, 35(1), 7-16. 